\title{
Temperature-dependent expression of different guanine- plus-cytosine content 16S rRNA genes in Haloarcula strains of the class Halobacteria
}

\author{
Yu Sato $\cdot$ Hiroyuki Kimura
}

Received: 13 June 2018/Accepted: 13 August 2018/Published online: 20 August 2018

(C) The Author(s) 2018

\begin{abstract}
Haloarcula strains, which are halophilic archaea, harbour two to three copies of 16S rRNA genes ( $r r s A, r r s B$ and $r r s C$ ) in their genomes. While $r r s B$ and $r r s C$ ( $r r s B$ ) show almost identical sequences, $r r s A$ shows $4-6 \%$ sequence difference and $1-3 \%$ guanine-plus-cytosine content $\left(P_{G C}\right)$ difference compared to $r r s B$. Based on the strong correlation between the $P_{G C}$ of $16 \mathrm{~S}$ rRNA genes and the growth temperatures of the prokaryotes, we hypothesised that high- $P_{G C} \operatorname{rrs} A$ and low- $P_{G C} \operatorname{rrs} B C$ are expressed at high and low temperatures, respectively. To verify the hypothesis, we performed sequence analyses and expression surveys of each 16S rRNA gene in eight Haloarcula strains. The
\end{abstract}

Electronic supplementary material The online version of this article (https://doi.org/10.1007/s10482-018-1144-3) contains supplementary material, which is available to authorized users.

\section{Y. Sato $\cdot$ H. Kimura}

Department of Environment and Energy Systems,

Graduate School of Science and Technology, Shizuoka

University, Shizuoka 422-8529, Japan

H. Kimura $(\bowtie)$

Department of Geosciences, Faculty of Science, Shizuoka University, 836 Oya, Suruga-ku, Shizuoka 422-8529, Japan

e-mail: kimura.hiroyuki@shizuoka.ac.jp

H. Kimura

Research Institute of Green Science and Technology,

Shizuoka University, Shizuoka 422-8529, Japan secondary structure prediction of the $16 \mathrm{~S}$ rRNA via computer simulation showed that the structural stability of $16 \mathrm{~S}$ rRNAs transcribed from $\operatorname{rrs} A$ was higher than that of $16 \mathrm{~S}$ rRNAs transcribed from $\operatorname{rrs} B C$. We measured expression levels of $r r s A$ and $r r s B C$ under various temperature conditions by reverse-transcriptase quantitative PCR. The expression ratio of high$P_{G C} r r s A$ to low- $P_{G C} r r s B C$ increased with cultivation temperatures in seven of eight Haloarcula strains. Our results suggest that the transcription of high- $P_{G C}$ rrs $A$ and low- $P_{G C} \operatorname{rrs} B C$ may be regulated in response to environmental temperature, and that $16 \mathrm{~S}$ rRNAs transcribed from high- $P_{G C}$ rrs $A$ function under high temperature conditions close to the maximum growth temperature.

Keywords 16S rRNA gene - Expression ·

Haloarcula $\cdot$ Guanine-plus-cytosine content · Thermal stability $\cdot$ Temperature

\section{Introduction}

Prokaryotes harbour 16S rRNA genes encoding rRNA in the small subunit of the prokaryotic ribosome, and the sequences are highly conserved. Therefore, the $16 \mathrm{~S}$ rRNA gene sequence is generally used for the identification of prokaryotes and for the assessment of prokaryotic diversity in various environments 
(Narihiro and Kamagata 2017; Yabe et al. 2017). A high percentage of prokaryotic genomes $(83 \%)$ contain two or more copies of 16S rRNA genes, and the sequences are nearly identical among the copies of 16S rRNA genes (Sun et al. 2013). However, recent genome analyses revealed that some prokaryotes show intragenomic heterogeneity of 16S rRNA genes (Větrovský and Baldrian 2013; Sun et al. 2013). In particular, halophilic archaea of the genus Haloarcula have long been known to harbour significantly different sequences of 16S rRNA genes in their genomes (Mevarech et al. 1989; Acinas et al. 2004; Boucher et al. 2004; Pei et al. 2010; Sun et al. 2013).

Haloarcula strains have been isolated from solar salterns and salt lakes in deserts (Juez et al. 1986; Oren et al. 1990), where large day-night temperature variations are observed (Wieland et al. 2005; Sima et al. 2013; Andrade et al. 2015; Naghoni et al. 2017). These strains have two or three copies of rRNA operons ( $r r n A, r r n B$ and $r r n C)$ in their genomes (Baliga et al. 2004; Liu et al. 2011; Ding et al. 2014; Yun et al. 2015; Sato et al. 2017). Each rRNA operon contains a 5S rRNA gene, a 16S rRNA gene ( $r r s$, $r r s B$ or $r r s C$, respectively) and a $23 \mathrm{~S}$ rRNA gene. The 5S rRNA gene sequences are almost identical among the rRNA operons. The 23S rRNA gene sequences show limited diversity (0.3-2\%). For 16S rRNA gene sequences, $r r s B$ and $r r s C$ ( $r r s B C$ ) show almost identical sequences, whereas $r r s A$ shows different sequences (4-6\%) from $r r s B$ (Mevarech et al. 1989; Mylvaganam and Dennis 1992; Dennis 1999; Sato et al. 2017). The different sequences of $16 \mathrm{~S}$ rRNA genes were first reported in Haloarcula marismortui (Mevarech et al. 1989). Adjacent regions such as the putative promoter of $16 \mathrm{~S}$ rRNA genes and the maturation process of the transcribed 16S rRNA have already been studied (Mylvaganam and Dennis 1992; Dennis et al. 1998; Dennis 1999; Amann et al. 2000). Previous studies showed that variation of the salinity in the medium did not change the expression level of each 16S rRNA gene in Haloarcula strains (LópezLópez et al. 2007; Cui et al. 2009). However, it has been reported that variation of the cultivation temperature changed the expression level of each 16S rRNA gene in H. marismortui (López-López et al. 2007).

It has been shown that $16 \mathrm{~S}$ rRNA gene sequences contain information regarding the thermal features of prokaryotes (Galtier and Lobry 1997; Khachane et al. 2005; Kimura et al. 2006; Wang et al. 2006; Kimura et al. 2010, 2013). Those findings were based on a high correlation between the guanine-plus-cytosine contents $\left(P_{G C}\right)$ of $16 \mathrm{~S}$ rRNA genes and the growth temperatures of archaea; the $P_{G C}$ of $16 \mathrm{~S}$ rRNA genes in thermophilic and hyperthermophilic archaea tend to be high, whereas the $P_{G C}$ of $16 \mathrm{~S}$ rRNA genes in psychrophilic and mesophilic archaea tend to be comparatively low (Kimura et al. 2007). On the basis of the relationship between the $P_{G C}$ of $16 \mathrm{~S}$ rRNA gene sequences and the growth temperatures of archaea, Kimura et al. (2013) proposed the microbial molecular thermometer (MMT), which uses linear regression equations to infer the minimum $\left(T_{\text {min }}\right)$, optimal $\left(T_{o p t}\right)$ and maximum $\left(T_{\max }\right)$ growth temperatures of cultured and not-yet cultured archaea based on the $P_{G C}$ value of each 16S rRNA gene.

Sato et al. (2017) used Haloarcula hispanica to verify a hypothesis that high- $P_{G C} \operatorname{rrs} A(58.9 \%)$ and low- $P_{G C} \operatorname{rrs} B C(56.4-56.5 \%)$ are expressed at high and low temperatures, respectively. They also investigated the physiological advantage of harbouring high- and low- $P_{G C} 16 \mathrm{~S}$ rRNA genes with respect to the growth of $H$. hispanica under various temperature conditions. An expression survey by reverse-transcriptase quantitative PCR (RT-qPCR) showed that the expression ratio of $r r s A$ to $r r s B C$ increased with the incubation temperature. At the $T_{\max }$, i.e., $50{ }^{\circ} \mathrm{C}$, the expression level of $r r s$ was significantly higher than those of $r r s B$. Sato et al. (2017) also constructed mutant strains with only one of three rRNA operons and cultivated the strains at various temperatures. The mutant strain harbouring only $r r n A$ including high$P_{G C} r r s A$ grew significantly slower than the wild-type strain at the $T_{\min } 25{ }^{\circ} \mathrm{C}$, but it grew as fast as the wildtype at $45{ }^{\circ} \mathrm{C}\left(T_{\text {opt }}\right)$ and $50{ }^{\circ} \mathrm{C}\left(T_{\max }\right)$. Sato et al. (2017) thus demonstrated that high- $P_{G C} 16 \mathrm{~S}$ rRNA is important for the rapid growth of $H$. hispanica at high temperature.

Haloarcula sp. CBA1115, Haloarcula japonica, Haloarcula argentinensis, Haloarcula amylolytica, Haloarcula quadrata, Haloarcula vallismortis and "Haloarcula californiae" also show different sequences of 16S rRNA genes as well as H. marismortui and H. hispanica (Javor et al. 1982; Takashina et al. 1990; Ihara et al. 1997; Oren et al. 1999; Yang et al. 2007; Yun et al. 2015). The sequence differences and the $P_{G C}$ offsets between $\operatorname{rrs} A$ and $r r s$ or $r r s C$ range from 4.8 to $5.6 \%$ and from 1.3 to $2.9 \%$, respectively (Sato et al. 2017). However, the 
temperature-dependent expression of $r r s A$ and $r r s B C$ in the members of the genus Haloarcula are not yet well understood.

Here, we investigated eight Haloarcula strains harbouring different sequences of 16S rRNA genes in their genomes (Sato et al. 2017). We sequenced the $16 \mathrm{~S}$ rRNA genes in each strain and estimated the $T_{\text {min }}$, $T_{\text {opt }}$ and $T_{\text {max }}$ based on the $P_{G C}$ of the 16S rRNA genes, using the MMT proposed by Kimura et al. (2013), in addition to measuring the growth temperatures by general cultivation methods. We also calculated the thermal stability of the secondary structure for each 16S rRNA transcribed from $r r s A, r r s B$ or $r r s C$ in the Haloarcula strains via computer simulation (in silico). The expression ratio of $r r s A$ to $r r s C$ was determined under various temperature conditions by RT-qPCR. We used the MMT, secondary structure analysis and RT-qPCR to test our hypothesis that Haloarcula strains express and use high- $P_{G C} 16 \mathrm{~S}$ rRNAs at high temperature and low- $P_{G C} 16 \mathrm{~S}$ rRNAs at low temperature.

\section{Materials and methods}

Haloarcula strains and culture conditions

Eight Haloarcula strains were used in this study: Haloarcula sp. CBA1115 JCM 30477, H. argentinensis JCM 9737, H. quadrata JCM 11048, H. vallismortis JCM 8877, H. amylolytica JCM 13557, H. japonica JCM 7785, H. hispanica JCM 8911 and " $H$. californiae" JCM 8912 were obtained from the Japan Collection of Microorganisms (JCM; Ibaraki, Japan). Each strain was cultured using JCM Medium 307: 2 g of casamino acid (BD, Franklin Lakes, NJ, USA), $2 \mathrm{~g}$ of Bacto yeast extract (BD), $1 \mathrm{~g}$ of sodium glutamate, $3 \mathrm{~g}$ of trisodium citrate, $10 \mathrm{~g}$ of $\mathrm{MgSO}_{4} \cdot 7 \mathrm{H}_{2} \mathrm{O}, 1 \mathrm{~g}$ of $\mathrm{CaCl}_{2} \cdot 2 \mathrm{H}_{2} \mathrm{O}, 1 \mathrm{~g}$ of $\mathrm{KCl}, 200 \mathrm{~g}$ of $\mathrm{NaCl}, 0.36 \mathrm{mg}$ of $\mathrm{FeCl}_{2} \cdot 4 \mathrm{H}_{2} \mathrm{O}$ and $0.36 \mathrm{mg}$ of $\mathrm{MnCl}_{2} \cdot 4 \mathrm{H}_{2} \mathrm{O}$ per a litre of distilled water.

The Haloarcula strains were incubated in the dark in $60 \mathrm{ml}$ screw-capped test tubes containing $20 \mathrm{ml}$ of JCM Medium 307 with shaking at 120 or $180 \mathrm{rpm}$ at $20,25,30,35,40,45,50,55$ and $60{ }^{\circ} \mathrm{C}$. The culture experiment was performed in quadruplicate. The optical density at $660 \mathrm{~nm}\left(\mathrm{OD}_{660}\right)$ of the cultures was monitored using a Spectronic 200 spectrophotometer (Thermo Fisher Scientific, Waltham, MA,
USA) against sterilised medium that was incubated under the same condition as a reference. The growth rates were calculated from $\mathrm{OD}_{660}$ values as described earlier (Sato et al. 2017). The actual $T_{\min }, T_{\text {opt }}$ and $T_{\max }$ were determined based on the growth rate at each temperature.

DNA extraction, 16S rRNA gene sequencing and sequence analyses

Cells of Haloarcula strains were inoculated into $60 \mathrm{ml}$ screw-capped test tubes containing $20 \mathrm{ml}$ of JCM Medium 307 and incubated in the dark with shaking at 120 or $180 \mathrm{rpm}$ at $40{ }^{\circ} \mathrm{C}$ for $100-150 \mathrm{~h}$. The cells were then collected by centrifugation at $12,000 \times g$ for $3 \mathrm{~min}$, and the pelleted cells were stored at $-25^{\circ} \mathrm{C}$ until DNA extraction.

DNA extraction from the pelleted cells was performed using the described methods with modifications (Tchinda et al. 2016; Sharmin et al. 2018). Briefly, the cells of Haloarcula strains were lysed by lysozyme and proteinase K. Bulk DNAs were extracted using both phenol/chloroform/isoamyl alcohol and chloroform/isoamyl alcohol and purified with ethanol precipitation. Next, 16S rRNA gene fragments were amplified by PCR with KOD -Plus- DNA polymerase (Toyobo, Osaka, Japan) from the bulk DNAs using a primer set $8 \mathrm{aF} / 1448 \mathrm{hR}$ (Table 1). The primer $1448 \mathrm{hR}$, which is specific for $16 \mathrm{~S}$ rRNA genes in Haloarcula strains, was designed using GenetyxMac ver. 19.0.1 software (Genetyx, Tokyo, Japan).

The PCR products were purified with a MicroSpin S-400 HR column (GE Healthcare, Little Chalfont, UK) or a QIAquick gel extraction kit (Qiagen, Hilden, Germany). The purified PCR products were cloned using a Zero Blunt TOPO PCR cloning kit (Life Technologies, Carlsbad, CA, USA) following the manufacturer's protocol. Insert DNA in each clone was sequenced by the dideoxy cycle-sequencing method using an Applied Biosystems 3730xl DNA analyzer (Life Technologies). We checked the sequences with the Bellerophon program (Huber et al. 2004) and no chimeric products were detected. We determined the current nearest relative of each $16 \mathrm{~S}$ rRNA gene by using the BLAST program (Altschul et al. 1990) and the sequences of $r r s A, r r s B$ and $r r s C$ in each strain were identified.

We deposited the 16S rRNA gene sequences of the Haloarcula strains in the DDBJ/EMBL/GenBank 
Table 1 Primers used for PCR, sequencing and RT-qPCR in this study

\begin{tabular}{|c|c|c|c|}
\hline Name & Sequence & Target (position) & References \\
\hline $8 \mathrm{aF}$ & $5^{\prime}$-TCY GGT TGA TCC TGC C-3' & Archaeal 16S rRNA gene (3-18) & Lefèvre et al. (2011) \\
\hline $1448 \mathrm{hR}$ & $5^{\prime}$-GGC TAC CTT GTT ACG ACT T-3' & $\begin{array}{l}\text { 16S rRNA gene of Haloarcula } \\
\text { strains (1424-1442) }\end{array}$ & This study \\
\hline $109 \mathrm{aF}$ & 5'-AMD GCT CAG TAA CAC GT-3' & Archaeal 16S rRNA gene (83-99) & Matsushita et al. (2016) \\
\hline $915 \mathrm{aR}$ & 5'-GTG CTC CCC CGC CAA TTC CT-3' & Archaeal 16S rRNA gene (858-877) & Matsushita et al. (2018) \\
\hline rrsAf & 5'-CGT CCA GCG GAA ACT GTC CGG-3' & $\begin{array}{l}\text { Partial sequence of } r r s A \text { in } \\
\text { Haloarcula strains (569-589) }\end{array}$ & Sato et al. (2017) \\
\hline rrsAr & $5^{\prime}$-CCG TCG GGT CCG TCT TCC TGA G-3' & $\begin{array}{l}\text { Partial sequence of } r r s A \text { in } \\
\text { Haloarcula strains }(674-695)\end{array}$ & Sato et al. (2017) \\
\hline rrsAf2 & 5'-CGT CCA GCG GAA ACT GTC AGG-3' & $\begin{array}{l}\text { Partial sequence of rrsA in } \\
\text { Haloarcula quadrata (569-589) }\end{array}$ & This study \\
\hline rrsAr2 & 5'-CCG TCG GGT CCG TCT TCT TGA G-3' & $\begin{array}{l}\text { Partial sequence of rrsA in } \\
\text { Haloarcula vallismortis (674-695) }\end{array}$ & This study \\
\hline $\operatorname{rrsBCf}$ & 5'-GGC GTC CGG TGG AAA CTA CAC AG-3' & $\begin{array}{l}\text { Partial sequence of } r r s B C \text { in } \\
\text { Haloarcula } \text { strains }(567-589)\end{array}$ & Sato et al. (2017) \\
\hline $\mathrm{rrsBCr}$ & $5^{\prime}$-CAC TGT CGG GTC CGG TCT CTC AAC-3' & $\begin{array}{l}\text { Partial sequence of } r r s B C \text { in } \\
\text { Haloarcula strains }(674-697)\end{array}$ & Sato et al. (2017) \\
\hline
\end{tabular}

database under Accession Nos. LC085248, LC085249 and LC198781 to LC198794 (Table S1).

We also performed sequence analyses of $16 \mathrm{~S}$ rRNA genes in other halophilic archaea. We obtained the sequences derived from 233 species in 58 genera in class Halobacteria from the DDBJ database and manually searched halophilic archaea with high intragenomic heterogeneity (more than $1 \%$ ) of $16 \mathrm{~S}$ rRNA genes. The sequence differences and $P_{G C}$ offsets among copies of their 16S rRNA genes in the halophilic archaea were calculated using GenetyxMac ver. 19.0.1 (Genetyx).

Estimation of growth temperatures

The 16S rRNA genes of thermophilic and hyperthermophilic archaea have higher $P_{G C}$ values compared to those of psychrophilic and mesophilic archaea (Galtier and Lobry 1997; Khachane et al. 2005; Kimura et al. 2007). Based on the strong correlation between the $P_{G C}$ values of $16 \mathrm{~S}$ rRNA genes and the growth temperatures of archaea, linear regression equations to estimate the $T_{\text {min }}, T_{o p t}$ and $T_{\text {max }}$ of archaea based on $P_{G C}$ of the $16 \mathrm{~S}$ rRNA genes have been proposed (Kimura et al. 2013). We manually selected the internal sequences between the Archaea-specific primers $109 \mathrm{aF}$ and $915 \mathrm{aR}$, used by Kimura et al. (2013), from the 16S rRNA gene sequences (Table 1). The $P_{G C}$ values of the internal sequences were calculated using Genetyx-Mac ver. 19.0.1 (Genetyx). The $T_{\text {min }}, T_{o p t}$ and $T_{\max }$ of eight Haloarcula strains were estimated based on the $P_{G C}$ of $r r s A, r r s B$ and $r r s C$ using the linear regression equations as follows.

$$
\begin{aligned}
T_{\text {min }} & =4.38( \pm 0.14) P_{G C}-225.3( \pm 8.5) \\
T_{\text {opt }} & =4.98( \pm 0.10) P_{G C}-241.6( \pm 5.9) \\
T_{\text {max }} & =4.89( \pm 0.11) P_{G C}-228.2( \pm 6.6)
\end{aligned}
$$

Prediction of 16S rRNA secondary structure and calculation for the structural stability

We used SSU-align ver. 0.1.1 to predict secondary structures of $16 \mathrm{~S}$ rRNAs transcribed from $r r s$, $r r s B$ and $\operatorname{rrs} C$ based on the sequences determined in this study (Narwocki 2009). In addition, we calculated the minimal folding free energy (MFE, $\Delta G$ in kcal mol${ }^{-1}$ ) value of each 16S rRNA with mfold web server ver. 2.3 (http://unafold.rna.albany.edu/?q=mfold/RNAFolding-Form2.3) to investigate the thermal stability of each 16S rRNA secondary structure (Zuker 2003). The nearly full-length $16 \mathrm{~S}$ rRNA sequences (approx. $1405 \mathrm{bp}$ ) determined in this study were used for the 
calculation. The sequence of $r r s C$ in $H$. hispanica (Accession No. LC085247) contains Y ( $\mathrm{T}$ or C) at position 392, and the nucleotide was $\mathrm{C}$ at the same position in $r r s C$ obtained from the complete genome (Liu et al. 2011). We therefore calculated the MFE value of $16 \mathrm{~S}$ rRNA transcribed from $r r s \mathrm{C}$ in $\mathrm{H}$. hispanica by using the sequence modified from $\mathrm{Y}$ to $\mathrm{C}$. The analyses using mfold web server were performed at the actual $T_{\text {min }}, T_{\text {opt }}$ and $T_{\max }$ of each strain. The significance of differences was determined by Student's $t$ test between MFE values of 16S rRNAs transcribed from $r r s A$ and $r r s B$ or $r r s C$ under same temperature condition.

Culture experiment to assess the expression of $16 \mathrm{~S}$ rRNA genes

Cells of Haloarcula strains were inoculated into $60 \mathrm{ml}$ screw-capped tubes containing $20 \mathrm{ml}$ of JCM Medium 307 . The cultures were incubated in the dark with shaking at 120 or $180 \mathrm{rpm}$ at 20, 25, 30, 35, 40, 45, 50 and $55{ }^{\circ} \mathrm{C}$. The $\mathrm{OD}_{660}$ of the cultures was monitored using a Spectronic 200 spectrophotometer (Thermo Fisher Scientific) against sterilised medium as a reference. When the cultures reached the early exponential growth phase $\left(\mathrm{OD}_{660}=0.15-0.40\right)$, the cells were collected by centrifugation at 6270 or $12,000 \times g$ for $3 \mathrm{~min}$. After the supernatants were discarded, the cells were treated with $100 \mu$ of RNA later (Life Technologies) and stored at $-85^{\circ} \mathrm{C}$ until RNA extraction.

Total RNA extraction and cDNA synthesis

We extracted total RNA from the pelleted cells by using a mirVana miRNA isolation kit (Ambion, Austin, TX, USA). Contaminating DNA in the RNA solution was removed with the TURBO DNA-free kit (Life Technologies). Total RNA was purified with an RNeasy MinElute cleanup kit (Qiagen). The quality and quantity of purified RNA were checked with both a NanoVue Plus spectrophotometer (GE Healthcare) and a 2100 Bioanalyzer (Agilent Technologies, Santa Clara, CA, USA). High-quality RNAs (RNA integrity number $>9.0$ ) were used to synthesise the singlestrand cDNA using a SuperScript III first strand synthesis system (Life Technologies). The cDNA was purified by a QIAquick PCR purification kit (Qiagen).
Quantitative PCR (qPCR)

A specific primer set rrsAf/rrsAr was used to quantify the expression level of rrsA in Haloarcula sp. CBA1115, $H$. argentinensis, $H$. amylolytica, $H$. japonica and " $H$. californiae" (Table 1 ). To measure the expression level of rrsA in $H$. quadrata and $H$. vallismortis, we designed two primers, rrsAf2 and rrsAr2, based on the sequences of rrsAf and rrsAr, respectively (Table 1 ). The primer sets, i.e., rrsAf2/ rrsAr and rrsAf/rrsAr2, were used to measure the expression level of rrsA in $H$. quadrata and $H$. vallismortis, respectively. The expression levels of $r r s B C$ were measured with the specific primer set rrsBCf/rrsBCr (Table 1).

To check the selectivity of these primer sets, we performed a qPCR with diluted PCR products $(1 / 100$, $1 / 1000,1 / 10,000$ and 1/100,000) of rrsA, rrsB and $r r s C$ (partial regions of 16S rRNA genes between the Archaea-specific primers, 109aF/915aR) amplified from the clone libraries constructed in this study. Each PCR mixture contained $2 \mu \mathrm{l}$ of diluted PCR products $(1 / 100,1 / 1000,1 / 10,000$ or $1 / 100,000), 2 \mu \mathrm{l}$ of each designed primer set (each $300 \mathrm{nM}$ ), $10 \mu \mathrm{l}$ of PowerUP SYBR Green master mix (Life Technologies) and $4 \mu \mathrm{l}$ of nuclease-free water. The qPCR was performed on an Applied Biosystems 7300 real time PCR system (Kataoka et al. 2018). The PCR cycling conditions included an initial step of $50{ }^{\circ} \mathrm{C}$ for $2 \mathrm{~min}$ and $95^{\circ} \mathrm{C}$ for 2 min followed by 40 cycles of $95{ }^{\circ} \mathrm{C}$ for $15 \mathrm{~s}, 58{ }^{\circ} \mathrm{C}$ for $15 \mathrm{~s}$ and $72{ }^{\circ} \mathrm{C}$ for $1 \mathrm{~min}$. Electrophoresis of PCR products was performed to check primer selectivity and no contamination.

The quantification of $r r s A$ and $r r s B$ contained in the cDNA samples was performed by the qPCR method described above. Each cDNA sample was tenfold diluted. The standard curves were prepared from diluted PCR products (1/100, 1/1000, 1/10,000 and $1 / 100,000$ ) of $r r s A, r r s B$ and $r r s C$ (partial regions of 16S rRNA genes between the Archaea-specific primers $109 \mathrm{aF} / 915 \mathrm{aR}$ ) as described above. Each PCR reaction was performed in triplicate for technical replicates. Quantification of $16 \mathrm{~S}$ rRNAs in $H$. japonica and $H$. argentinensis was performed in two batches for biological replicates. The significance of differences was calculated by Student's $t$ test among the results under different temperature conditions. 


\section{Results and discussion}

Actual growth temperatures of the Haloarcula strains

Maximum growth rate and $\mathrm{OD}_{660}$ value of Haloarcula strains at each temperature are shown in Figs. S1 and S2. The growth temperatures of the eight Haloarcula strains are summarised in Table 2. H. quadrata and "H. californiae" grew at $20-45{ }^{\circ} \mathrm{C}$ with optimal growth at $40{ }^{\circ} \mathrm{C}$. This result is not consistent with an earlier study in which $H$. quadrata grew up to $55^{\circ} \mathrm{C}$ (Oren et al. 1999). H. argentinensis, H. vallismortis, $H$. amylolytica, $H$. japonica and $H$. hispanica grew from 20 to $50{ }^{\circ} \mathrm{C}$, with optimal growth at $45{ }^{\circ} \mathrm{C}$. The growth temperatures of Haloarcula sp. CBA1115 ranged from 20 to $55^{\circ} \mathrm{C}$, and the $T_{\max }$ is the highest growth temperature among the eight Haloarcula strains examined here.

Sequence analyses of 16S rRNA genes in the Haloarcula strains and other halophilic archaea

Almost full-length 16S rRNA genes (1405 bp) were amplified from bulk DNAs of Haloarcula strains, and clone libraries were constructed. We randomly selected and sequenced a total of 16 clones in each clone library. The BLAST analysis revealed that the 16S rRNA genes mostly matched with $r r s$, $r r s B$ and

Table 2 Actual growth ranges and optima, $P_{G C}$ of 16S rRNA genes ( $\left.r r s\right)$ and estimated growth ranges and optima for Haloarcula strains

\begin{tabular}{|c|c|c|c|c|c|c|c|c|c|}
\hline \multirow[t]{2}{*}{ Strain } & \multirow[t]{2}{*}{$\begin{array}{l}\text { JCM } \\
\text { no. }\end{array}$} & \multicolumn{3}{|c|}{$\begin{array}{l}\text { Actual growth ranges and } \\
\text { optima }^{\mathrm{a}}\end{array}$} & \multicolumn{2}{|c|}{ 16S rRNA } & \multicolumn{3}{|c|}{ Estimated growth ranges and optima ${ }^{\mathrm{d}}$} \\
\hline & & $\begin{array}{l}T_{\min } \\
\left({ }^{\circ} \mathrm{C}\right)\end{array}$ & $\begin{array}{l}T_{o p t} \\
\left({ }^{\circ} \mathrm{C}\right)\end{array}$ & $\begin{array}{l}T_{\max } \\
\left({ }^{\circ} \mathrm{C}\right)\end{array}$ & Type & $\begin{array}{l}P_{G C}^{\mathrm{c}} \\
(\%)\end{array}$ & $T_{\min }\left({ }^{\circ} \mathrm{C}\right)$ & $T_{\text {opt }}\left({ }^{\circ} \mathrm{C}\right)$ & $T_{\max }\left({ }^{\circ} \mathrm{C}\right)$ \\
\hline \multirow[t]{3}{*}{ Haloarcula amylolytica } & \multirow[t]{3}{*}{13557} & \multirow[t]{3}{*}{20} & \multirow[t]{3}{*}{45} & \multirow[t]{3}{*}{50} & $\operatorname{rrs} A$ & 58.6 & $31.4 \pm 16.7$ & $50.3 \pm 11.8$ & $58.4 \pm 13.1$ \\
\hline & & & & & $r r s B$ & 56.2 & $21.0 \pm 16.4$ & $38.4 \pm 11.5$ & $46.7 \pm 12.8$ \\
\hline & & & & & $r r s C$ & 56.2 & $21.0 \pm 16.4$ & $38.4 \pm 11.5$ & $46.7 \pm 12.8$ \\
\hline \multirow[t]{2}{*}{ Haloarcula japonica } & \multirow[t]{2}{*}{7785} & \multirow[t]{2}{*}{20} & \multirow[t]{2}{*}{45} & \multirow[t]{2}{*}{50} & $r r s A$ & 58.5 & $30.9 \pm 16.7$ & $49.7 \pm 11.7$ & $57.9 \pm 13.1$ \\
\hline & & & & & $r r s C$ & 56.4 & $21.7 \pm 16.4$ & $39.3 \pm 11.5$ & $47.6 \pm 12.8$ \\
\hline \multirow[t]{3}{*}{ Haloarcula hispanica } & \multirow[t]{3}{*}{8911} & \multirow[t]{3}{*}{20} & \multirow[t]{3}{*}{45} & \multirow[t]{3}{*}{50} & $r r s A^{\mathrm{b}}$ & 58.9 & $32.6 \pm 16.7$ & $51.6 \pm 11.8$ & $59.7 \pm 13.1$ \\
\hline & & & & & $r r s B^{\mathrm{b}}$ & 56.5 & $22.2 \pm 16.4$ & $39.8 \pm 11.6$ & $48.1 \pm 12.8$ \\
\hline & & & & & $r r s C^{\mathrm{b}}$ & 56.4 & $21.7 \pm 16.4$ & $39.3 \pm 11.5$ & $47.6 \pm 12.8$ \\
\hline \multirow{3}{*}{$\begin{array}{l}\text { Haloarcula sp. } \\
\text { CBA1115 }\end{array}$} & \multirow[t]{3}{*}{30477} & \multirow[t]{3}{*}{20} & \multirow[t]{3}{*}{50} & \multirow[t]{3}{*}{55} & $r r s A$ & 59.0 & $33.1 \pm 16.7$ & $52.2 \pm 11.8$ & $60.3 \pm 13.1$ \\
\hline & & & & & $r r s B$ & 56.1 & $20.4 \pm 16.4$ & $37.8 \pm 11.5$ & $46.1 \pm 12.8$ \\
\hline & & & & & $r r s C$ & 56.1 & $20.4 \pm 16.4$ & $37.8 \pm 11.5$ & $46.1 \pm 12.8$ \\
\hline \multirow{2}{*}{$\begin{array}{l}\text { Haloarcula } \\
\text { argentinensis }\end{array}$} & \multirow[t]{2}{*}{9737} & \multirow[t]{2}{*}{20} & \multirow[t]{2}{*}{45} & \multirow[t]{2}{*}{50} & $\operatorname{rrs} A$ & 58.5 & $30.9 \pm 16.7$ & $49.7 \pm 11.7$ & $57.8 \pm 13.1$ \\
\hline & & & & & $r r s B$ & 56.5 & $22.2 \pm 16.4$ & $39.8 \pm 11.6$ & $48.1 \pm 12.8$ \\
\hline \multirow[t]{2}{*}{ Haloarcula quadrata } & \multirow[t]{2}{*}{11048} & \multirow[t]{2}{*}{20} & \multirow[t]{2}{*}{40} & 45 & $r r s A$ & 58.5 & $30.9 \pm 16.7$ & $49.7 \pm 11.7$ & $57.8 \pm 13.1$ \\
\hline & & & & & $r r s B$ & 56.7 & $23.2 \pm 16.4$ & $40.9 \pm 11.6$ & $49.2 \pm 12.8$ \\
\hline Haloarcula vallismortis & 8877 & 20 & 45 & 50 & $r r s A$ & 58.4 & $30.3 \pm 16.7$ & $49.1 \pm 11.7$ & $57.2 \pm 13.0$ \\
\hline & & & & & $r r s B$ & 57 & $24.3 \pm 16.5$ & $42.2 \pm 11.6$ & $50.4 \pm 12.9$ \\
\hline "Haloarcula & 8912 & 20 & 40 & 45 & $r r s A$ & 58.4 & $30.3 \pm 16.7$ & $49.1 \pm 11.7$ & $57.2 \pm 13.0$ \\
\hline california & & & & & $r r s B$ & 56.4 & $21.5 \pm 16.4$ & $39.3 \pm 11.5$ & $47.6 \pm 12.8$ \\
\hline
\end{tabular}

${ }^{a}$ Actual growth ranges and optima were determined by cultivation with JCM Medium 307 in this study

${ }^{\mathrm{b}} 16 \mathrm{~S}$ rRNA gene sequences of $H$. hispanica were quoted from Sato et al. (2017)

${ }^{\mathrm{c}} P_{G C}$ values were calculated from partial sequences of $16 \mathrm{~S}$ rRNA genes between primers $109 \mathrm{aF}$ and $915 \mathrm{aR}$

${ }^{\mathrm{d}}$ Estimated growth temperatures were calculated from $P_{G C}$ of $r r s A, r r s B$ and $r r s C$ using the microbial molecular thermometer (MMT) of Kimura et al. (2013) 
rrsC of the Haloarcula strains registered in the DDBJ/ EMBL/GenBank database (Table S1). While $r r s B$ and $r r s C$ show nearly identical sequences, the sequence of rrsA was 4.6-6.0\% (65-85 bp) different from those of $r r s B C$ in the eight Haloarcula strains.

We also performed sequence analyses of $16 \mathrm{~S}$ rRNA genes in other halophilic archaea and found 26 strains (representing 14 genera) with highly different sequences of $16 \mathrm{~S}$ rRNA genes (more than 1.0\%) (Table S2). Notably, five strains belonging to genera Halomicrobium and Halosimplex (5.8-8.7\%) show higher sequence differences of 16S rRNA genes compared with Haloarcula strains (4.8-5.6\%). On the other hand, $P_{G C}$ offsets among the $16 \mathrm{~S}$ rRNA genes are less than $1.7 \%$ in these halophilic archaea compared with Haloarcula strains.

Estimation of the growth temperatures based on the $P_{G C}$ of the $16 \mathrm{~S}$ rRNA genes

We selected the internal sequences between the Archaea-specific primers 109aF and 915aR (795 bp) to estimate the growth temperatures of the Haloarcula strains, using the linear regression equations proposed previously (Kimura et al. 2013). The $P_{G C}$ of the internal sequences of $r r s A$ ranged from 58.4 to $59.0 \%$ (Table 2). The $P_{G C}$ of the internal sequences of $r r s B$ and $r r s C$ ranged from 56.1 to $57.0 \%$. The minimum and maximum $P_{G C}$ offsets between $r r s A$ and $r r s B$ were $1.4 \%$ and $2.9 \%$ in $H$. vallismortis and Haloarcula sp. CBA1115, respectively.

The approximate growth temperatures were estimated based on the $P_{G C}$ values of the partial $16 \mathrm{~S}$ rRNA gene sequences (Table 2). The $T_{\text {opt }}$ estimated based on the $P_{G C}$ of rrsA in each Haloarcula strain ranged from 49.1 to $52.2{ }^{\circ} \mathrm{C}$, whereas the $T_{o p t}$ estimated based on the $P_{G C}$ of $r r s B$ or $r r s C$ in each Haloarcula strain ranged from 37.8 to $42.2{ }^{\circ} \mathrm{C}$. Actual $T_{o p t}$ were typically temperatures between the estimated $T_{o p t}$ from the $P_{G C}$ of $r r s A$ and $r r s B C$. The offsets between $T_{o p t}$ estimated based on $P_{G C}$ of $r r s A$ and $r r s B C$ in Haloarcula strains were $6.9-14.4{ }^{\circ} \mathrm{C}$. These results indicate that harbouring high- and low- $P_{G C} 16 \mathrm{~S}$ rRNA genes may enable Haloarcula strains to rapidly grow under a wide range of temperature conditions.
Prediction of the secondary structures of $16 \mathrm{~S}$ rRNAs in the Haloarcula strains

We summarised different positions between secondary structures of $16 \mathrm{~S}$ rRNAs predicted from $r r s A$ and $r r s B$ or $r r s C$ in Haloarcula strains (Figs. 1, 2). The majority of differences (49-60\%) were observed in helices 21,22 and 26 of the central domain. A previous study showed that the affinity of ribosomal protein $\mathrm{S} 8$ to helix 21 in thermophiles and hyperthermophiles is much higher than that in mesophiles (Gruber et al. 2003). Furthermore, another study suggests that formation of helix 26 is essential for assembly of functional small subunit of ribosomes in Escherichia coli (Xu and Culver 2010). Therefore, these regions may be important in determining the functional differences among $16 \mathrm{~S}$ rRNAs transcribed from rrsA and $r r s B$.

The thermal stability of each $16 \mathrm{~S}$ rRNA secondary structure was predicted with the use of the mfold web server (Table 3 ). The calculation results showed that the MFE values of the $16 \mathrm{~S}$ rRNAs transcribed from $r r s A$ were significantly lower than those of the $16 \mathrm{~S}$ rRNAs transcribed from $r r s B$ and $r r s C$ under the same temperature conditions ( $p<0.05$ by Student's $t$ test). These results suggest that the thermal stability of the secondary structure of the $16 \mathrm{~S}$ rRNAs transcribed from high- $P_{G C} r r s A$ is greater than those of the $16 \mathrm{~S}$ rRNAs transcribed from low- $P_{G C} r r s B$ or $r r s C$.

Expression of $r r s A$ and $r r s B C$ under various temperature conditions

The selectivity of the primer sets used in this study was verified by qPCR using PCR product of $r r s A, r r s B$ or $r r s C$ amplified from the clone libraries constructed in this study (Fig. S3). Proper products were amplified from only rrsA in $H$. quadrata, rrsA in $H$. vallismortis and $r r s A$ in the other Haloarcula strains using the primer sets, rrsAf2/rrsAr, rrsAf/rrsAr2 and rrsAf/ rrsAr, respectively. Proper products were amplified from only $r r s B$ and $r r s C$ in all Haloarcula strains using the primer set rrsBCf/rrsBCr. In addition, melting curve analyses showed that the melting temperature of the products from $r r s A$ is about $1{ }^{\circ} \mathrm{C}$ higher than those of products from $r r s B$ or $r r s C$ in all Haloarcula strains. These results suggest that all of the primer sets were well designed to precisely amplify $r r s A$ or $r r s C$. 
a

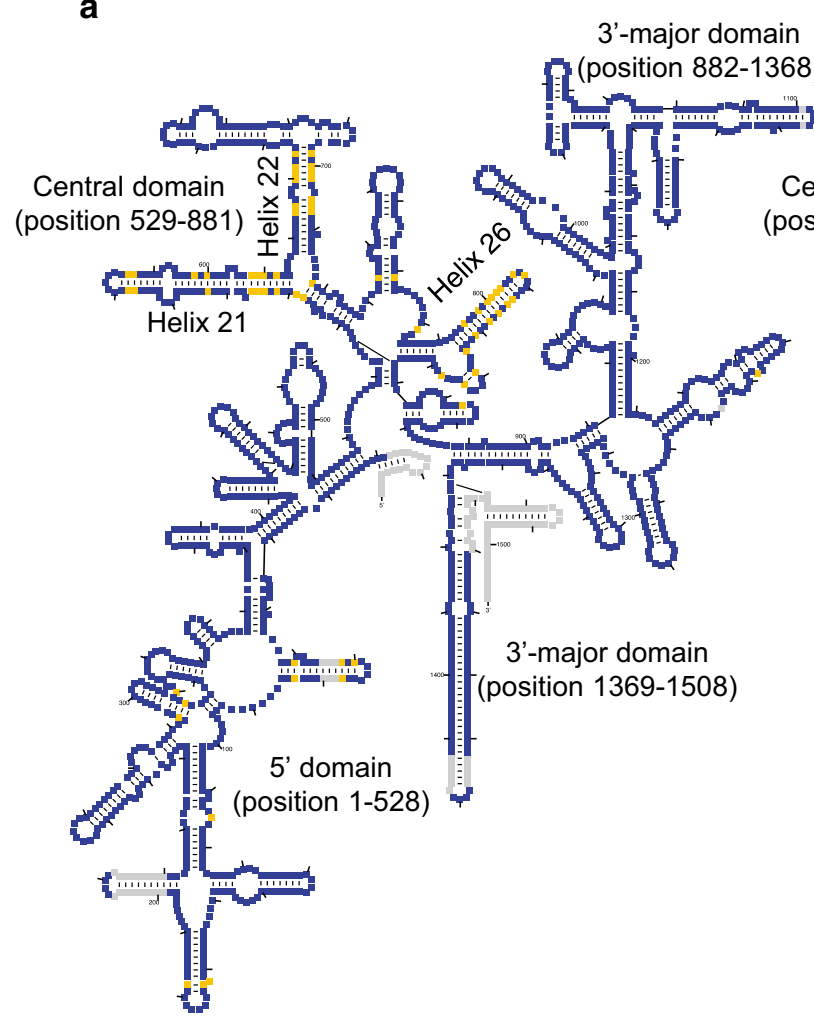

b

3'-major domain 8)

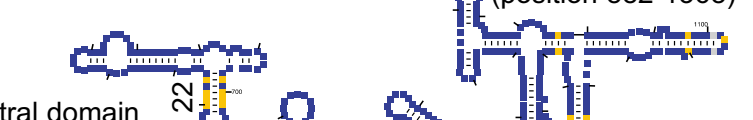

C

3'-major domain

d

3'-major domain
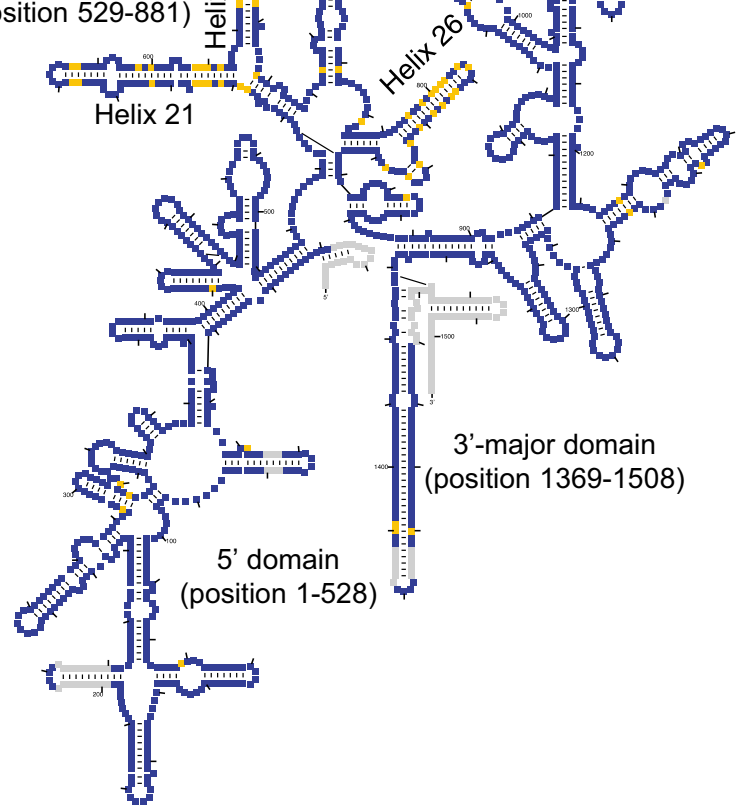

(position 1369-1508)

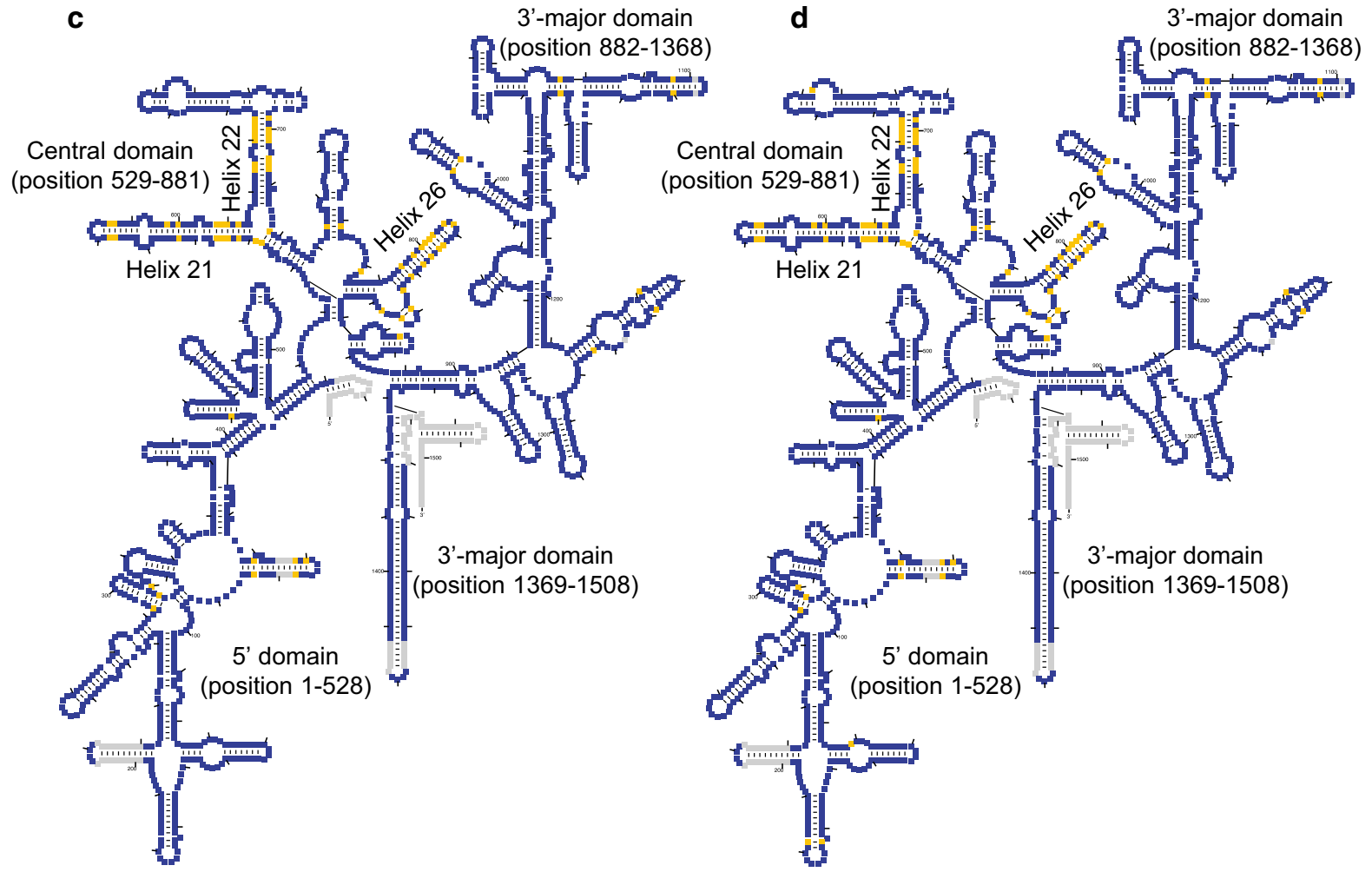


४Fig. 1 Secondary structure of $16 \mathrm{~S}$ rRNAs in a Haloarcula amylolytica, b $H$. japonica, c $H$. hispanica and d Haloarcula sp. CBA1115. Yellow colour represents different positions between secondary structures of $16 \mathrm{~S}$ rRNAs transcribed from rrsA and $r r s B$ or $r r s$. Gray colour represents gap between the sequences of $16 \mathrm{~S}$ rRNA in Haloarcula strains and consensus sequence of archaeal $16 \mathrm{~S}$ rRNA

We quantified each 16S rRNA in Haloarcula strains by using RT-qPCR. No significant differences were found between biological replicates. The results of our RT-qPCR suggest that the expression levels of rrs $A$ and $r r s B C$ in seven of the Haloarcula strains varied depending on the incubation temperatures (Fig. 3). The expression ratio of $r r s A$ to $r r s B C$ ( $r r s A$ :rrs $B C$ ratio) in particular increased with the cultivation temperature, and the maximum expression ratios were observed at each $T_{\max }$. We were able to divide the expression patterns in the Haloarcula strains into three types. First, the expression ratios continuously increased with temperature. This expression pattern was observed in $H$. amylolytica, $H$. japonica and $H$. hispanica (Fig. 3a-c). Although the expression ratio did not vary at temperatures close to $T_{\text {opt }}$ and $T_{\text {max }}$, the ratio at $T_{\max }$ was significantly higher than those below $40{ }^{\circ} \mathrm{C}(p<0.05$ by Student's $t$ test $)$. Second, the expression ratios increased suddenly at $T_{\text {max }}$ in Haloarcula sp. CBA1115, H. argentinensis, $H$. quadrata and H. vallismortis (Fig. 3d-g). This ratio at $T_{\text {max }}$ was significantly higher than those at other tested temperatures ( $p<0.05$ by Student's $t$ test). Third, the expression ratio stayed constant under all tested temperatures in "H. californiae" (Fig. 3h).

Although we observed differences in the expression levels of $r r s A$ and $r r s B$, all eight of the Haloarcula strains simultaneously expressed these 16S rRNA genes at all tested temperatures. The $\operatorname{rrs} A$ : $r r s C$ ratio increased with temperature in seven of the eight Haloarcula strains (Fig. 3). A previous study using $H$. marismortui also showed that the expression ratio of a high- $P_{G C} 16 \mathrm{~S}$ rRNA gene compared to low- $P_{G C} 16 \mathrm{~S}$ rRNA genes increased markedly at $T_{\max }\left(50{ }^{\circ} \mathrm{C}\right)$ (López-López et al. 2007). Our present findings extend those of the previous study and suggest that the expression ratios of high- $P_{G C} 16 \mathrm{~S}$ rRNA genes to low- $P_{G C} 16 \mathrm{~S}$ rRNA genes increase with temperature in most Haloarcula strains. The variation in expression ratios may occur due to temperature-dependent expression of 16S rRNA genes and/or thermal degradation of $16 \mathrm{~S}$ rRNAs with low stability transcribed from $r r s C$ at high temperatures. Moreover, we observed that the expression ratios at $20{ }^{\circ} \mathrm{C}$ and $25{ }^{\circ} \mathrm{C}$ ranged from 0.28 to 0.59 in seven Haloarcula strains, which suggests that the total expression of $r r s B$ and $r r s C$ was 1.7 to 3.6 times as much as that of $r r s$. Low- $P_{G C} 16 \mathrm{~S}$ rRNA gene can be transcribed and replicated with low energy costs because of two reasons. First, costs for de novo production of adenine, thymine and uracil is lower than those of guanine and cytosine (Chen et al. 2016). Second, force for unwinding adenine-thymine rich region is lower than that for unwinding guanine-cytosine rich regions (Bockelmann et al. 1997; Essevaz-Roulet et al. 1997; Bockelmann et al. 1998; Rief et al. 1999). Therefore, low- $P_{G C} r r s B$ and $r r s C$ in Haloarcula strains can help to reduce energy consumption in transcription and replication under low temperature conditions, which might explain why total expression of $\operatorname{rrs} B$ and $\operatorname{rrs} C$ increased at low temperatures close to the actual $T_{\text {min }}$ in seven of the eight Haloarcula strains. Although the expression mechanisms of these 16S rRNA genes are unclear, they can be verified in future studies.

High temperature adaptation of Haloarcula strains in their habitats

Sato et al. (2017) constructed rRNA operon doublemutant strains of $H$. hispanica that harbour only $r r A$ including high- $P_{G C} \operatorname{rrs} A(58.9 \%)$ or only $r r n C$ including low- $P_{G C} r r s C(56.4 \%)$. Both mutant strains grew slower than the wild-type strain at low temperature close to the $T_{\min }$, whereas the mutant harbouring $r r n A$ containing only high- $P_{G C} r r s A$ grew as fast as the wild-type strain at high temperature close to the $T_{\text {opt }}$ and $T_{\text {max }}$. Their findings suggest that rRNA transcribed from the rRNA operon containing high- $P_{G C}$ rrsA is important for growth at high temperature in $H$. hispanica.

In the present study, the $\operatorname{rrs} A$ :rrs $B C$ ratios increased with the incubation temperature in six Haloarcula strains as well as H. hispanica (Fig. 3). The results of the secondary structure prediction in silico indicate that $16 \mathrm{~S}$ rRNAs transcribed from high- $P_{G C} r r s A$ in Haloarcula strains can form a more stable secondary structure at high and low temperatures compared to those transcribed from low- $P_{G C} \operatorname{rrs} B C$. In addition, only Haloarcula sp. CBA1115 harbouring the highest 
a

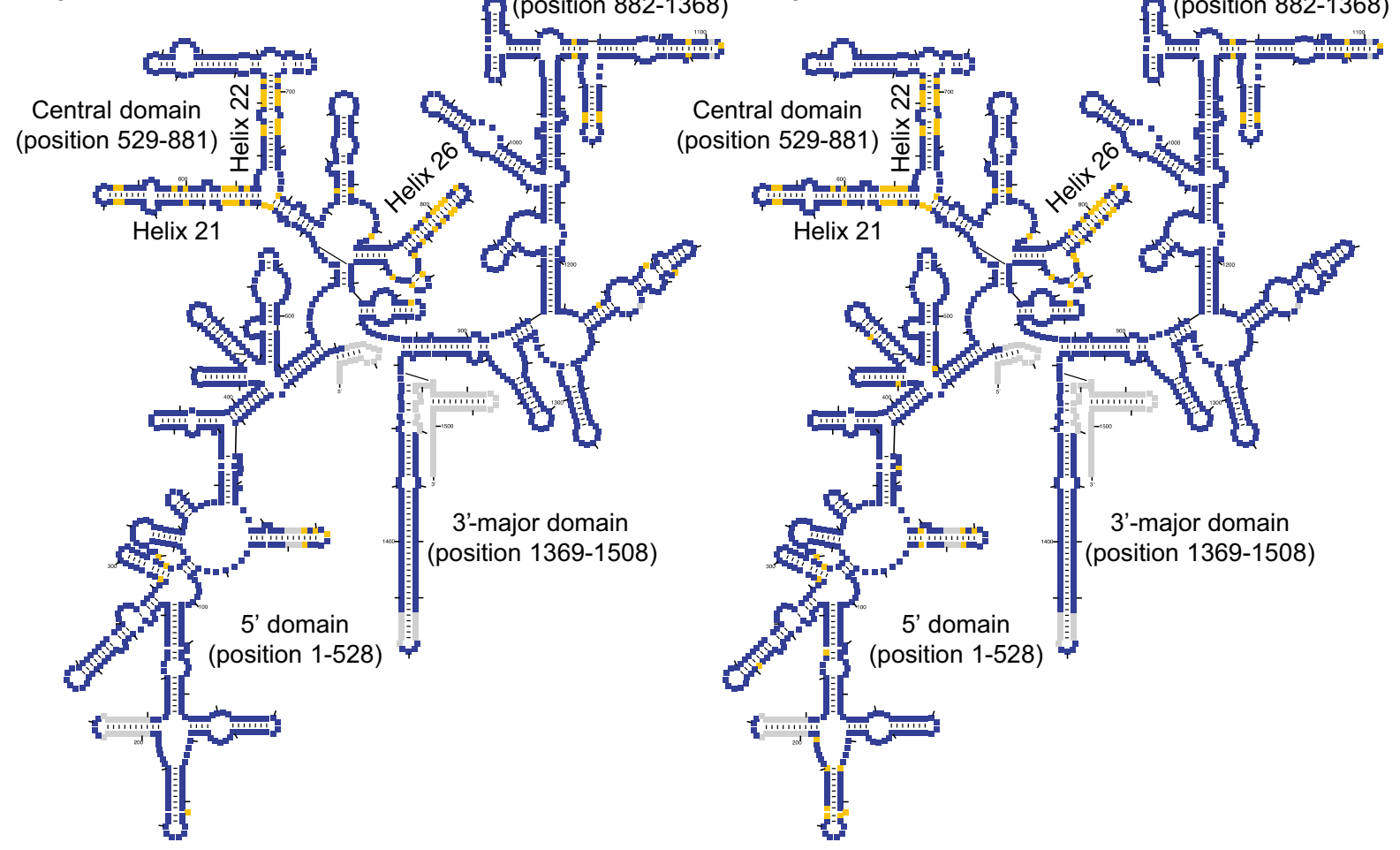

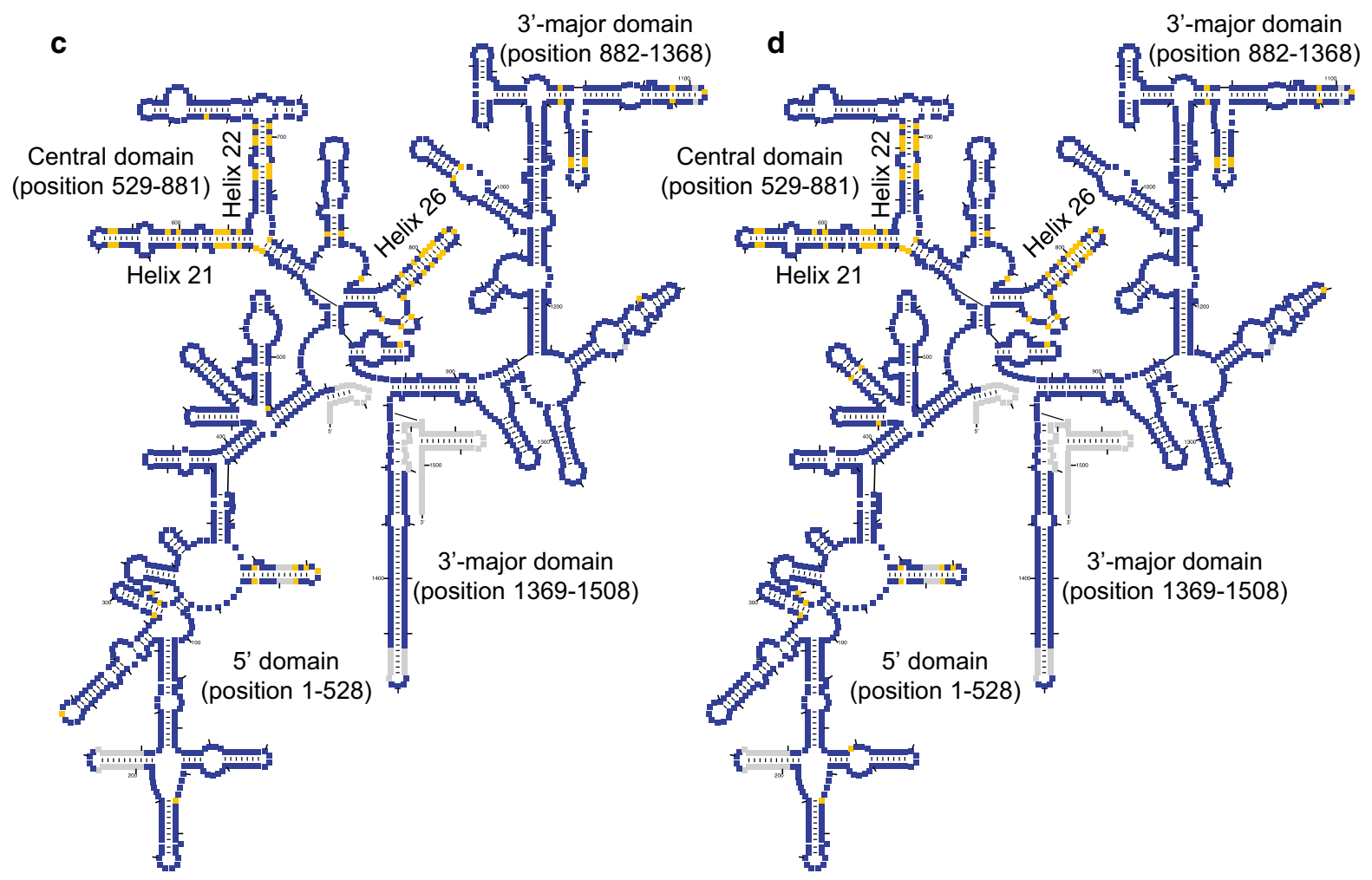


4Fig. 2 Secondary structure of 16S rRNAs in a Haloarcula argentinensis, b $H$. quadrata, c $H$. vallismortis and $\mathbf{d}$ " $H$. californiae". Yellow colour represents different positions between secondary structures of $16 \mathrm{~S}$ rRNAs transcribed from rrsA and $r r s$. Gray colour represents gap between the sequences of $16 \mathrm{~S}$ rRNAs in Haloarcula strains and consensus sequence of archaeal $16 \mathrm{~S}$ rRNA

$P_{G C}(59.0 \%)$ of $16 \mathrm{~S}$ rRNA gene grew at $55^{\circ} \mathrm{C}$, the highest growth temperature among the Haloarcula strains reported previously (Bowers and Wiegel 2011; Namwong et al. 2011). These findings imply that $16 \mathrm{~S}$ rRNAs transcribed from high- $P_{G C} r r s A$ are potentially important for growth at high temperatures close to actual $T_{\max }\left(45-55^{\circ} \mathrm{C}\right)$ in the Haloarcula strains inhabiting solar salterns and salt lakes, where environmental temperature varies greatly in a day (Wieland et al. 2005; López-López et al. 2007; Sima et al. 2013; Andrade et al. 2015).

\section{Conclusion}

In this study, we performed the sequencing of $16 \mathrm{~S}$ rRNA genes in eight Haloarcula strains, and we estimated the growth temperatures using MMT based on the $P_{G C}$ values of the $16 \mathrm{~S}$ rRNA gene sequences. The estimated growth temperatures of cells carrying the high- $P_{G C} 16 \mathrm{~S}$ rRNA gene ( $r r s A$ ) were approximately $6-15{ }^{\circ} \mathrm{C}$ higher than those carrying the low$P_{\mathrm{GC}} 16 \mathrm{~S}$ rRNA genes ( $r r s B$ and $r r s C$ ). In addition, the prediction analysis via computer simulation revealed that the stability of the secondary structure of $16 \mathrm{~S}$ rRNAs transcribed from high- $P_{G C}$ rrsA was higher than that of $16 \mathrm{~S}$ rRNAs transcribed from low- $P_{G C}$ $r r s B C$ in the Haloarcula strains examined in this study, suggesting that small ribosomal subunits containing those $16 \mathrm{~S}$ rRNAs may function effectively under various temperature conditions. These results suggest that Haloarcula strains harbour different sequences of $16 \mathrm{~S}$ rRNA genes to maintain rapid growth over a wide range of temperatures.

We characterised the expression of $r r s A$ and $r r s B C$ of $H$. hispanica at different growth temperatures. We found that the expression ratio of high- $P_{G C}$ rrs $A$ to low- $P_{G C} r r s B C$ increased with the incubation temperature in seven of the eight Haloarcula strains. Our results indicate that the temperature-dependent expression of $16 \mathrm{~S}$ rRNA genes is a common feature in most Haloarcula strains. The environmental
Table 3 Minimum folding free energy values calculated from 16S rRNA sequences of Haloarcula strains at the minimum $\left(T_{\text {min }}\right)$, optimal $\left(T_{\text {opt }}\right)$ and maximum $\left(T_{\max }\right)$ growth temperature

\begin{tabular}{|c|c|c|c|c|}
\hline \multirow[t]{2}{*}{ Strain } & \multirow[t]{2}{*}{ Type } & \multicolumn{3}{|c|}{ Minimum folding free energy $\left(\mathrm{kcal} \mathrm{mol}^{-1}\right)$} \\
\hline & & $T_{\min }$ & $T_{\text {opt }}$ & $T_{\max }$ \\
\hline \multirow[t]{3}{*}{ Haloarcula sp. CBA1115 } & $\operatorname{rrs} A$ & -786.5 & -403.8 & -343.0 \\
\hline & $r r s B$ & -767.1 & -389.2 & -329.2 \\
\hline & $r r s C$ & -764.3 & -387.6 & -327.8 \\
\hline \multirow[t]{2}{*}{ Haloarcula argentinensis } & $r r s A$ & -784.1 & -461.9 & -401.7 \\
\hline & $r r s B$ & -762.9 & -442.2 & -381.2 \\
\hline \multirow[t]{2}{*}{ Haloarcula quadrata } & $r r s A$ & -768.3 & -512.0 & -450.9 \\
\hline & $r r s B$ & -759.2 & -503.0 & -441.1 \\
\hline \multirow[t]{2}{*}{ Haloarcula vallismortis } & $r r s A$ & -786.6 & -464.8 & -404.2 \\
\hline & $r r s B$ & -774.7 & -452.7 & -392.6 \\
\hline \multirow[t]{3}{*}{ Haloarcula amylolytica } & $r r s A$ & -776.2 & -460.2 & -400.3 \\
\hline & $r r s B$ & -766.0 & -448.0 & -388.7 \\
\hline & $r r s C$ & -756.7 & -440.7 & -381.8 \\
\hline \multirow[t]{2}{*}{ Haloarcula japonica } & $r r s A$ & -783.2 & -462.3 & -402.0 \\
\hline & $r r s C$ & -755.8 & -439.7 & -380.5 \\
\hline \multirow[t]{3}{*}{ Haloarcula hispanica } & $r r s A$ & -788.2 & -466.4 & -405.9 \\
\hline & $r r s B$ & -767.2 & -446.7 & -387.5 \\
\hline & $r r s C$ & -763.5 & -440.3 & -381.2 \\
\hline "Haloarcula californiae" & $r r s A$ & -780.1 & -523.0 & -461.4 \\
\hline
\end{tabular}



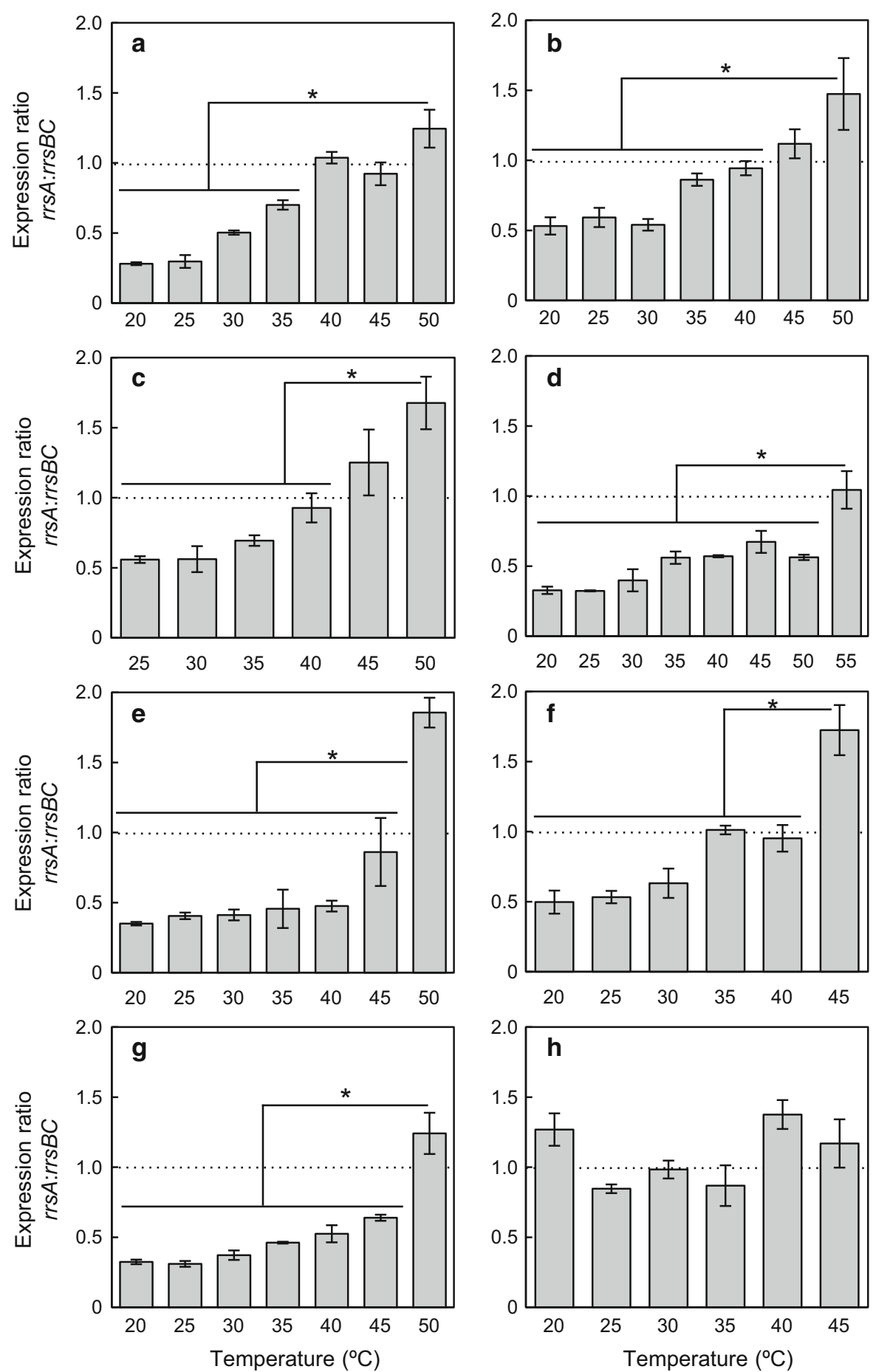

Fig. 3 Expression ratio of $r r s A$ to $\operatorname{rrs} B C$ ( $r r s A$ :rrsBC) under various temperature conditions in a Haloarcula amylolytica, b $H$. japonica, c $H$. hispanica, d Haloarcula sp. CBA1115, e $H$. argentinensis, f $H$. quadrata, g $H$. vallismortis and $\mathbf{h}$ " $H$.

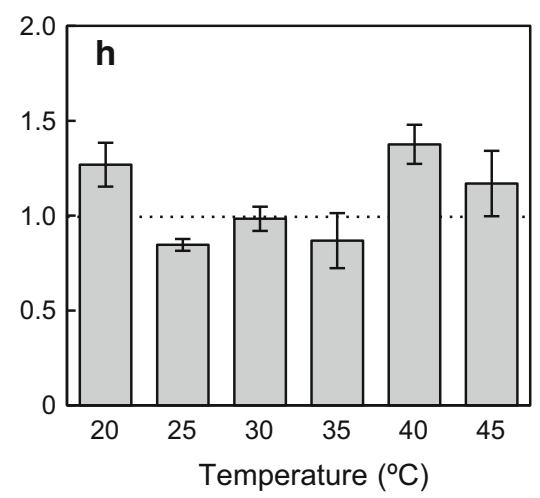

californiae". Error bars denote the standard deviation for triplicate measurements. The results for $H$. hispanica (c) are taken from Sato et al. (2017). Asterisks indicate significant differences among samples (Student's $t$ test, $p<0.05$ ) 
temperature in salt lakes and solar salterns varies in a day, and Haloarcula strains may express and utilise different $P_{G C}$ of $16 \mathrm{~S}$ rRNAs in response to variable temperature in their habitats.

Acknowledgements This work was supported by Japan Society for the Promotion of Science KAKENHI Grants (Nos. 23657016 and 17K19346).

Conflict of interest The authors declare that they have no conflict of interest.

Open Access This article is distributed under the terms of the Creative Commons Attribution 4.0 International License (http:// creativecommons.org/licenses/by/4.0/), which permits unrestricted use, distribution, and reproduction in any medium, provided you give appropriate credit to the original author(s) and the source, provide a link to the Creative Commons license, and indicate if changes were made.

\section{References}

Acinas SG, Marcelino LA, Klepac-Ceraj V, Polz MF (2004) Divergence and redundancy of $16 \mathrm{~S}$ rRNA sequences in genomes with multiple rrn operons. J Bacteriol 186:2629-2635. https://doi.org/10.1128/JB.186.9.26292635.2004

Altschul SF, Gish W, Miller W, Myers EW, Lipman DJ (1990) Basic local alignment search tool. J Mol Biol 215:403-410. https://doi.org/10.1016/S0022-2836(05)80360-2

Amann G, Stetter KO, Llobet-Brossa E, Amann R, Antón J (2000) Direct proof for the presence and expression of two $5 \%$ different 16S rRNA genes in individual cells of Haloarcula marismortui. Extremophiles 4:373-376. https://doi.org/10.1007/s007920070007

Andrade K, Logemann J, Heidelberg KB, Emerson JB, Comolli LR, Hug LA, Probst AJ, Keillar A, Thomas BC, Miller CS, Allen EE, Moreau JW, Brocks JJ, Banfield JF (2015) Metagenomic and lipid analyses reveal a diel cycle in a hypersaline microbial ecosystem. ISME J 9:2697-2711. https://doi.org/10.1038/ismej.2015.66

Baliga NS, Bonneau R, Facciotti MT, Pan M, Glusman G, Deutsch EW, Shannon P, Chiu Y, Weng RS, Gan RR, Hung P, Date SV, Marcotte E, Hood L, Ng WV (2004) Genome sequence of Haloarcula marismortui: a halophilic archaeon from the Dead Sea. Genome Res 14:2221-2234. https://doi.org/10.1101/gr.2700304

Bockelmann U, Essevaz-Roulet B, Heslot F (1997) Molecular stick-slip motion revealed by opening DNA with piconewton forces. Phys Rev Lett 79:4489-4492. https:// doi.org/10.1103/PhysRevLett.79.4489

Bockelmann U, Essevaz-Roulet B, Heslot F (1998) DNA strand separation studied by single molecule force measurements. Phys Rev E 58:2386-2394. https://doi.org/10.1103/ PhysRevE.58.2386

Boucher Y, Douady CJ, Sharma AK, Kamekura M, Doolittle WF (2004) Intragenomic heterogeneity and intergenomic recombination among haloarchaeal rRNA genes. J Bacteriol 186:3980-3990. https://doi.org/10.1128/JB.186.12. 3980-3990.2004

Bowers KJ, Wiegel J (2011) Temperature and pH optima of extremely halophilic archaea: a mini-review. Extremophiles 15:119-128. https://doi.org/10.1007/s00792-0100347-y

Chen WH, Lu G, Bork P, Hu S, Lercher MJ (2016) Energy efficiency trade-offs drive nucleotide usage in transcribed regions. Nat Commun 7:11334. https://doi.org/10.1038/ ncomms 11334

Cui HL, Zhou PJ, Oren A, Liu SJ (2009) Intraspecific polymorphism of 16S rRNA genes in two halophilic archaeal genera, Haloarcula and Halomicrobium. Extremophiles 13:31-37. https://doi.org/10.1007/s00792-008-0194-2

Dennis PP (1999) Expression of ribosomal RNA operons in halophilic archaea. In: Oren A (ed) Microbiology and biogeochemistry of hypersaline environments. CRC Press, Boca Raton, pp 319-330

Dennis PP, Ziesche S, Mylvaganam S (1998) Transcription analysis of two disparate rRNA operons in the halophilic archaeon Haloarcula marismortui. J Bacteriol 180:4804-4813

Ding J-Y, Chiang P-W, Hong M-J, Dyall-Smith M, Tang S-L (2014) Complete genome sequence of the extremely halophilic archaeon Haloarcula hispanica strain N601. Genome Announc 2:e0178-14. https://doi.org/10.1128/ genomeA.00178-14

Essevaz-Roulet B, Bockelmann U, Heslot F (1997) Mechanical separation of the complementary strands of DNA. Proc Natl Acad Sci USA 94:11935-11940. https://doi.org/10. 1073/pnas.94.22.11935

Galtier N, Lobry JR (1997) Relationships between genomic $\mathrm{G}+\mathrm{C}$ content, RNA secondary structures, and optimal growth temperature in prokaryotes. $\mathrm{J}$ Mol Evol 44:632-636. https://doi.org/10.1007/PL00006186

Gruber T, Ko C, Lung B, Shcherbakov D, Piendl W (2003) Affinity of ribosomal protein S8 from mesophilic and (hyper) thermophilic archaea and bacteria for $16 \mathrm{~S}$ rRNA correlates with the growth temperatures of the organisms. FEMS Microbiol Lett 549:123-128. https://doi.org/10. 1016/S0014-5793(03)00760-9

Huber T, Faulkner G, Hugenholtz P (2004) Bellerophon: a program to detect chimeric sequences in multiple sequence alignments. Bioinformatics 20:2317-2319. https://doi.org/ 10.1093/bioinformatics/bth226

Ihara K, Watanabe S, Tamura T (1997) Haloarcula argentinensis sp. nov. and Haloarcula mukohataei sp. nov., two new extremely halophilic archaea collected in Argentina. Int J Syst Bacteriol 47:73-77. https://doi.org/10.1099/ 00207713-47-1-73

Javor B, Requadt C, Stoeckenius W (1982) Box-shaped halophilic bacteria. J Bacteriol 151:1532-1542

Juez G, Rodriguez-Valera F, Ventosa A, Kushner DJ (1986) Haloarcula hispanica spec. nov. and Haloferax gibbonsii spec, nov., two new species of extremely halophilic archaebacteria. Syst Appl Microbiol 8:75-79. https://doi. org/10.1016/S0723-2020(86)80152-7

Kataoka T, Mitsunobu S, Hamamura N (2018) Influence of the chemical form of antimony on soil microbial community 
structure and arsenite oxidation activity. Microbes Environ 33:214-221. https://doi.org/10.1264/jsme2.ME17182

Khachane AN, Timmis KN, dos Santos VAPM (2005) Uracil content of $16 \mathrm{~S}$ rRNA of thermophilic and psychrophilic prokaryotes correlates inversely with their optimal growth temperatures. Nucleic Acids Res 33:4016-4022. https:// doi.org/10.1093/nar/gki714

Kimura H, Sugihara M, Kato K, Hanada S (2006) Selective phylogenetic analysis targeted at 16S rRNA genes of thermophiles and hyperthermophiles in deep-subsurface geothermal environments. Appl Environ Microbiol 72:21-27. https://doi.org/10.1128/AEM.72.1.21-27.2006

Kimura H, Ishibashi J, Masuda H, Kato K, Hanada S (2007) Selective phylogenetic analysis targeting 16S rRNA genes of hyperthermophilic archaea in the deep-subsurface hot biosphere. Appl Environ Microbiol 73:2110-2117. https:// doi.org/10.1128/AEM.02800-06

Kimura H, Mori K, Tashiro T, Kato K, Yamanaka T, Ishibashi J, Hanada S (2010) Culture-independent estimation of optimal and maximum growth temperatures of archaea in subsurface habitats based on the $\mathrm{G}+\mathrm{C}$ content in $16 \mathrm{~S}$ rRNA gene sequences. Geomicrobiol J 27:114-122. https://doi.org/10.1080/01490450903456699

Kimura H, Mori K, Yamanaka T, Ishibashi J (2013) Growth temperatures of archaeal communities can be estimated from the guanine-plus-cytosine contents of 16S rRNA gene fragments. Environ Microbiol Rep 5:468-474. https://doi. org/10.1111/1758-2229.12035

Lefèvre CT, Frankel RB, Pósfai M, Prozorov T, Bazylinski DA (2011) Isolation of obligately alkaliphilic magnetotactic bacteria from extremely alkaline environments. Environ Microbiol 13:2342-2350. https://doi.org/10.1111/j.14622920.2011.02505.X

Liu H, Wu Z, Li M, Zhang F, Zheng H, Han J, Liu J, Zhou J, Wang S, Xiang H (2011) Complete genome sequence of Haloarcula hispanica, a model haloarchaeon for studying genetics, metabolism, and virus-host interaction. J Bacteriol 193:6086-6087. https://doi.org/10.1128/JB.05953-11

López-López A, Benlloch S, Bonfá M, Rodríguez-Valera F, Mira A (2007) Intragenomic 16S rDNA divergence in Haloarcula marismortui is an adaptation to different temperatures. J Mol Evol 65:687-696. https://doi.org/10.1007/ s00239-007-9047-3

Matsushita M, Ishikawa S, Nagai K, Hirata Y, Ozawa K, Mitsunobu S, Kimura H (2016) Regional variation of $\mathrm{CH}_{4}$ and $\mathrm{N}_{2}$ production processes in the deep aquifers of an accretionary prism. Microbes Environ 31:329-338. https://doi. org/10.1264/jsme2.ME16091

Matsushita M, Magara K, Sato Y, Shinzato N, Kimura H (2018) Geochemical and Microbiological evidence for microbial methane production in deep aquifers of the Cretaceous accretionary prism. Microbes Environ 33:205-213. https:// doi.org/10.1264/jsme2.ME17199

Mevarech M, Hirsch-Twizer S, Goldman S, Yakobson E, Eisenberg H, Dennis PP (1989) Isolation and characterization of the rRNA gene clusters of Halobacterium marismortui. J Bacteriol 171:3479-3485

Mylvaganam S, Dennis PP (1992) Sequence heterogeneity between the two genes encoding 16S rRNA from the halophilic archaebacterium Haloarcula marismortui. Genetics 130:399-410
Naghoni A, Emtiazi G, Amoozegar MA, Cretoiu MS, Stal LJ, Etemadifar Z, Shahzadeh Fazeli SA, Bolhuis H (2017) Microbial diversity in the hypersaline Lake Meyghan, Iran. Sci Rep 7:11522. https://doi.org/10.1038/s41598-01711585-3

Namwong S, Tanasupawat S, Kudo T, Itoh T (2011) Haloarcula salaria sp. nov. and Haloarcula tradensis sp. nov., isolated from salt in Thai fish sauce. Int J Syst Evol Microbiol 61:231-236. https://doi.org/10.1099/ijs.0.021790-0

Narihiro T, Kamagata Y (2017) Genomics and metagenomics in microbial ecology: recent advances and challenges. Microbes Environ 32:1-4. https://doi.org/10.1264/jsme2. ME3201rh

Narwocki EP (2009) Structural RNA homology search and alignment using covariance models. Ph.D. thesis, Washington University School of Medicine, Saint Louis, MO, USA

Oren A, Ginzburg M, Ginzburg BZ, Hochstein LI, Volcani BE (1990) Haloarcula marismortui (Volcani) sp. nov., nom. rev., an extremely halophilic bacterium from the Dead Sea. Int J Syst Bacteriol 40:209-210. https://doi.org/10.1099/ 00207713-40-2-209

Oren A, Ventosa A, Gutiérrez MC, Kamekura M (1999) Haloarcula quadrata sp. nov., a square, motile archaeon isolated from a brine pool in Sinai (Egypt). Int J Syst Bacteriol 49:1149-1155. https://doi.org/10.1099/ 00207713-49-3-1149

Pei AY, Oberdorf WE, Nossa CW, Agarwal A, Chokshi P, Gerz EA, Jin Z, Lee P, Yang L, Poles M, Brown SM, Sotero S, DeSantis T, Brodie E, Nelson K, Pei Z (2010) Diversity of 16S rRNA genes within individual prokaryotic genomes. Appl Environ Microbiol 76:3886-3897. https://doi.org/10. 1128/AEM.02953-09

Rief M, Clausen-Schaumann H, Gaub HE (1999) Sequencedependent mechanics of single DNA molecules. Nat Struct Biol 6:346-349. https://doi.org/10.1038/7582

Sato Y, Fujiwara T, Kimura H (2017) Expression and function of different guanine-plus-cytosine content $16 \mathrm{~S}$ rRNA genes in Haloarcula hispanica at different temperatures. Front Microbiol 8:482. https://doi.org/10.3389/fmicb. 2017.00482

Sharmin D, Guo Y, Nishizawa T, Ohshima S, Sato Y, Takashima Y, Narisawa K, Ohta H (2018) Comparative genomic insights into endofungal lifestyles of two bacterial endosymbionts, Mycoavidus cysteinexigens and Burkholderia rhizoxinica. Microbes Environ 33:66-76. https://doi.org/10.1264/jsme2.ME17138

Sima S, Ahmadalipour A, Tajrishy M (2013) Mapping surface temperature in a hyper-saline lake and investigating the effect of temperature distribution on the lake evaporation. Remote Sens Environ 136:374-385. https://doi.org/10. 1016/j.rse.2013.05.014

Sun D-L, Jiang X, Wu QL, Zhou N-Y (2013) Intragenomic heterogeneity of $16 \mathrm{~S}$ rRNA genes causes overestimation of prokaryotic diversity. Appl Environ Microbiol 79:5962-5969. https://doi.org/10.1128/AEM.01282-13

Takashina T, Hamamoto T, Otozai K, Grant WD, Horikoshi K (1990) Haloarcula japonica sp. nov., a new triangular halophilic archaebacterium. Syst Appl Microbiol 13:177-181. https://doi.org/10.1016/S07232020(11)80165-7 
Tchinda RA, Boudjeko T, Simao-Beaunoir AM, Lerat S, Tsala É, Monga E, Beaulieu C (2016) Morphological, physiological, and taxonomic characterization of actinobacterial isolates living as endophytes of cacao pods and cacao seeds. Microbes Environ 31:56-62. https://doi.org/10. 1264/jsme2.ME15146

Větrovský T, Baldrian P (2013) The variability of the 16S rRNA gene in bacterial genomes and its consequences for bacterial community analyses. PLoS ONE 8:e57293. https:// doi.org/10.1371/journal.pone.0057923

Wang HC, Susko E, Roger AJ (2006) On the correlation between genomic $\mathrm{G}+\mathrm{C}$ content and optimal growth temperature in prokaryotes: data quality and confounding factors. Biochem Biophys Res Commun 342:681-684. https://doi.org/10.1016/j.bbrc.2006.02.037

Wieland A, Zopfi J, Benthien M, Kühl M (2005) Biogeochemistry of an iron-rich hypersaline microbial mat (Camargue, France). Microb Ecol 49:34-49. https://doi.org/10.1007/ s00248-003-2033-4
Xu Z, Culver GM (2010) Differential assembly of 16S rRNA domains during $30 \mathrm{~S}$ subunit formation. RNA 16:1990-2001. https://doi.org/10.1261/rna.2246710

Yabe S, Sakai Y, Abe K, Yokota A (2017) Diversity of Ktedonobacteria with Actinomycetes-like morphology in terrestrial environments. Microbes Environ 32:61-70. https:// doi.org/10.1264/jsme2.ME16144

Yang Y, Cui H-L, Zhou P-J, Liu S-J (2007) Haloarcula amylolytica sp. nov., an extremely halophilic archaeon isolated from Aibi salt lake in Xin-Jiang, China. Int J Syst Evol Microbiol 57:103-106. https://doi.org/10.1099/ijs.0. 64647-0

Yun J-H, Song HS, Roh SW, Jung M-J, Kim PS, Bae J-W (2015) Complete genome sequence of Haloarcula sp. CBA1115 isolated from non-purified solar salts. Mar Genomics 23:19-21. https://doi.org/10.1016/j.margen.2015.03.012

Zuker M (2003) Mfold web server for nucleic acid folding and hybridization prediction. Nucleic Acids Res 31:3406-3415. https://doi.org/10.1093/nar/gkg595 